\title{
CONFLITOS DE INTERESSE ENTRE PEQUENOS PRODUTORES RURAIS E A CONSERVAÇÃO DE ÁREAS DE PRESERVAÇÃO PERMANENTE NA MATA ATLÂNTICA
}

\author{
Gisele Garcia Alarcon¹, Ângela da Veiga Beltrame ${ }^{2}$, Karen Follador Karam ${ }^{3}$ \\ 1Bióloga, M.Sc., Doutoranda em Recursos Genéticos Vegetais, UFSC, Florianópolis, SC, Brasil - giselegalarcon@ yahoo.com \\ ${ }^{2}$ Eng a . Agrônoma, Dra ${ }^{\mathrm{a}}$, Depto. de Geociências, UFSC, Florianópolis, SC, Brasil - beltrame@ @fh.ufsc.br \\ ${ }^{3}$ Antropóloga, Dra , Florianópolis, SC, Brasil - karenkaram@uol.com.br
}

Recebido para publicação: 09/05/2009 - Aceito para publicação: 01/09/2009

\begin{abstract}
Resumo
As Áreas de Preservação Permanente (APP) foram instituídas pelo Código Florestal Brasileiro de 1965. Embora seus objetivos sejam proteger os cursos d'água, as APPs têm gerado conflitos com os interesses de pequenos produtores rurais, principalmente na Mata Atlântica. Em São Bonifácio, as características geográficas e histórico-culturais permitem extrapolar os resultados obtidos para outros municípios localizados na Mata Atlântica. Neste estudo avaliou-se o histórico (1950 a 2000) de uso do solo nas APPs em São Bonifácio, procurando identificar conflitos e percepções dos agricultores quanto à legislação ambiental. Os resultados demonstraram a intensificação de uso das APPs, sendo as margens de rios as mais utilizadas (61\%). Os topos de morro sofreram um declínio de área destinada à agricultura entre 1950 e 2000 (15\%), mas foram ocupados pelo reflorestamento a partir de 1990. As nascentes e áreas com declividade acima de $45^{\circ}$ apresentam as melhores condições, com $70 \%$ e $80 \%$ de cobertura vegetal, respectivamente. Os resultados permitem avaliar a baixa efetividade das leis ambientais para a conservação na pequena propriedade. A fiscalização segue modelos punitivos, que desaceleram o desmatamento, mas não o evitam por completo e não possibilitam a valorização dos recursos florestais.

Palavras-chave: Áreas de preservação permanente; legislação ambiental; pequenos produtores rurais; conflitos ambientais.
\end{abstract}

\begin{abstract}
Conflicts of interests between small agriculturist and the permanent preservation areas' conservation in the Atlantic Forest. The Permanent Preservation Areas (PPA) were established by the Brazilian Forest Code in 1965. Although its objective is to protect the water resources, the PPA have caused conflicts with small agriculturists, especially in the Atlantic Forest. In São Bonifácio, the geographic and historic-cultural characteristics allow to compare the results with other municipalities located in the Atlantic Forest. In this study it was evaluated the PPA use between 1950 and 2000, the conflicts related to it and the small agriculturists perception regarding the environmental legislation. The results pointed out the permanent preservation areas use intensification, being the riparian forests the most used $(61 \%)$. The mountains' peaks registered a decline of areas used for agriculture, between 1950 and $2000(15 \%)$, and a rise of reforestation with exotic species after 1990. The water spring and areas above $45^{\circ}$ declination have the best conditions, with $70 \%$ and $80 \%$ of vegetation cover, respectively. The results point out the environmental laws low effectiveness for the conservation in small properties. The fiscalization is based on punitive methods, which slows down the deforestation, but does not stop it completely neither stimulate the forest resources valorization.
\end{abstract}

Keywords: Permanent preservation; environmental legislation; small land owners; environmental conflicts.

\section{INTRODUÇÃO}

O Código Florestal (Lei n $\left.{ }^{\circ} 4.771 / 1965\right)$ é um dos principais instrumentos que normatiza o uso e a conservação de florestas no Brasil, a partir da instituição das Áreas de Preservação Permanente (APP) e da Reserva Legal. 
Com o advento do Código Florestal nos anos 60, a floresta passou a ser entendida como um bem jurídico, responsável pela manutenção dos ecossistemas, através da proteção dos recursos hídricos e da biodiversidade, da estabilidade geológica, da manutenção da paisagem, da proteção do solo e do bemestar das populações humanas. Com isso, o proprietário rural tornou-se gestor dos recursos naturais, e o direito de propriedade deixou de ser interpretado exclusivamente a partir da concepção privatista do Código Civil (BORGES, 1999).

Essas transformações no meio rural induzem à possibilidade de redirecionar os rumos do desenvolvimento em benefício das gerações futuras, embora alguns autores chamem a atenção para o fato de que os mecanismos concebidos para se alcançar tais objetivos podem trazer danos às gerações atuais de muitos pequenos produtores rurais ${ }^{1}$ (NEUMANN; LOCH, 2002; TRENTINI, 2004; SALES, 2003).

Para os pequenos produtores rurais, destinar $20 \%$ de sua propriedade à Reserva Legal e respeitar as APPs representa uma diminuição das áreas destinadas à produção e, consequentemente, interfere diretamente na renda familiar (NEUMANN; LOCH, 2002).

Os principais conflitos originados a partir do Código Florestal estão relacionados à linearidade e à rigidez dessa lei. Para Neumann; Loch (2002), a linearidade com que as APPs são aplicadas, além de descartar as diferenças geográficas do Brasil, não considera as características polifuncionais do meio rural, o que torna a diferenciação entre pequenos, médios e grandes produtores inócua frente aos critérios da legislação ambiental. A linearidade das APPs resulta em choque de interesses com as práticas agrícolas de grande parcela de pequenos produtores rurais localizados em áreas ecologicamente sensíveis, como é o caso da maior parte do contingente de agricultores familiares do sul do Brasil, que vivem na área de domínio do bioma Mata Atlântica.

Os problemas gerados a partir da legislação ambiental com pequenos produtores rurais agravamse nas áreas de Mata Atlântica em função de três aspectos principais: a) a importância biológica do bioma; b) o fato de abrigar $70 \%$ da população brasileira; e c) o fato de restarem apenas $7 \%$ de sua cobertura vegetal original (MITTERMEIER, et al., 2005). No caso de Santa Catarina, somam-se a esses aspectos o tamanho das propriedades (entre as 203 mil propriedades rurais do estado, estima-se que 182 mil possuem menos de 50 hectares, conforme CEPA, 2002) e a condição de que todo o estado está inserido no bioma Mata Atlântica.

A partir dos conflitos registrados em diversas regiões entre pequenos produtores rurais e a legislação ambiental, especialmente após os anos 1990, novas normatizações surgiram com o intuito de minimizar os impactos da linearidade das leis ambientais para pequenos produtores rurais. A Medida Provisória no 2.166 (2001), a Resolução do CONAMA no 369 (2006), a Lei da Mata Atlântica (Lei Federal $\mathrm{n}^{\circ}$ 11.428, de 2006) e, mais recentemente, em Santa Catarina, a Portaria da FATMA $\mathrm{n}^{\circ}$ 18, de 2008, preveem o cômputo da Reserva Legal nas Áreas de Preservação Permanente e possibilidades de uso sustentável das APPs, frente a critérios específicos, para produtores com propriedades com até 50 hectares.

A despeito dos avanços legais e das possibilidades de minimização de conflitos e convergência de interesses entre o uso e a conservação dos recursos florestais em pequenas propriedades rurais, poucos esforços vêm sendo realizados para a divulgação e implementação das novas normas legais promulgadas, e os problemas entre pequenos produtores rurais e a legislação ambiental vêm se agravando à medida que a fiscalização ambiental tem sido intensificada (ALARCON, 2007).

São Bonifácio, localizado em Santa Catarina, está quase que inteiramente inserido na região ecológica da Floresta Ombrófila Densa e, por suas características, que remontam ao período da colonização alemã nos estados do sul do Brasil, a população rural é predominantemente formada por pequenos produtores rurais. Essas características, associadas à presença da maior e uma das mais importantes unidades de conservação estaduais no município, o Parque Estadual da Serra do Tabuleiro, refletem sobremaneira as dificuldades vivenciadas por pequenos produtores rurais com relação à legislação ambiental.

O presente estudo teve como objetivo identificar o estado de conservação das áreas de preservação permanente, verificar as transformações no uso e cobertura do solo nelas ocorridas ao longo das últimas cinco décadas e avaliar os conflitos existentes entre agricultores familiares e a legislação

\footnotetext{
${ }^{1}$ Na Lei da Reforma Agrária (Lei no 8.639, de 1993) está definido que as pequenas propriedades rurais possuem área compreendida de 1 (um) até 4 (quatro) módulos fiscais.
} 
ambiental em uma microbacia de São Bonifácio, que assume as características e problemas típicos de um município rural de Santa Catarina.

\section{MATERIAIS E MÉTODOS}

\section{Área de estudo}

O município de São Bonifácio encontra-se na região da Grande Florianópolis, a 80 quilômetros da capital. Possui 460 quilômetros de área e cerca de $21 \%$ de seu território faz parte do Parque Estadual da Serra do Tabuleiro ${ }^{2}$.

Segundo Klein (1978), São Bonifácio encontra-se na área de Domínio do Bioma Mata Atlântica e possui duas regiões ecológicas: a região ecológica da Floresta Ombrófila Densa (FOD) e a região ecológica da Floresta Ombrófila Mista (FOM, Floresta de Araucárias). Na região ecológica da Floresta Ombrófila Densa são encontradas cinco formações florestais, sendo que três delas ocorrem no município de São Bonifácio: a FOD Submontana, a FOD Montana e a FOD Altomontana.

O município é formado por 15 microbacias hidrográficas (Figura 1). A microbacia (MB) do Rio Sete possui $60 \mathrm{~km}^{2}$, e lá residem 118 famílias (EPAGRI, 2005). A MB está totalmente inserida na região ecológica da Floresta Ombrófila Densa (KLEIN, op. cit.).

Com relação ao meio socioeconômico, São Bonifácio sofreu um processo de redução populacional $(8,3 \%)$ entre os anos de 1970 e 2000. O município possui 3.218 habitantes, predominando a população rural (80\%) (IBGE, 2000). É marcante o número de estabelecimentos menores de 100 ha e a predominância da agricultura familiar.

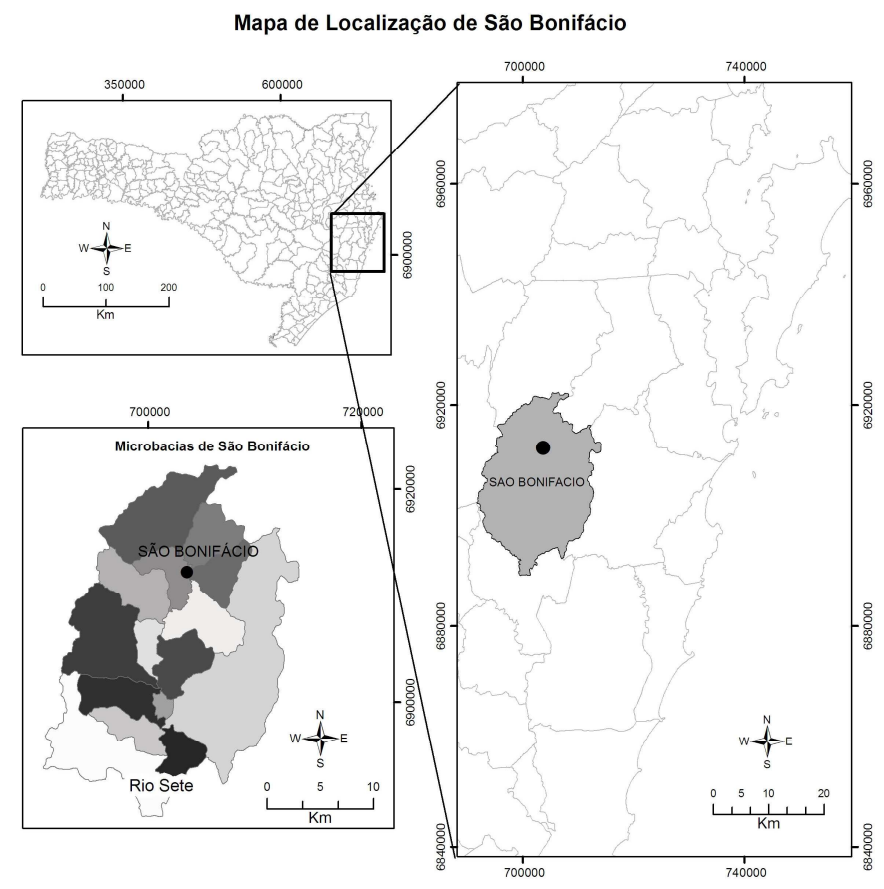

Figura 1. Localização de São Bonifácio.

Figure 1. Localization of the study area.

O setor secundário é o que apresenta maior expressividade na arrecadação de tributos, sendo a indústria madeireira a de maior destaque. Entretanto, é o setor primário que mantém a maior parte da população ocupada (IBGE, 2003). A bovinocultura é a principal atividade pecuária, e as 15 mil cabeças de gado concedem ao município o $1^{\circ}$ lugar desse setor na região (CEPA, 2006).

\footnotetext{
${ }^{2}$ O Parque Estadual da Serra do Tabuleiro foi criado em 1 de novembro de 1975, através do Decreto Estadual no 1.260 (SANTA CATARINA, 1975). Sua gestão é realizada pela Fundação Estadual de Meio Ambiente (FATMA).
} 
Na microbacia do Rio Sete, o setor primário ocupa quase todas as famílias de agricultores, sendo a bovinocultura leiteira e a produção de feijão, milho, fumo e mandioca as atividades de maior destaque (EPAGRI, 2005).

\section{Procedimentos metodológicos \\ Cartografia}

O material cartográfico contou com fotografias aéreas da região da microbacia do Rio Sete dos anos de 1957, 1978 e 2002, as quais foram georreferenciadas com apoio de coleta de dados em campo. A fotointerpretação das fotografias aéreas foi realizada no Programa ArcGis 9.1 da ESRI Gis and Mapping Software. Para cada ano analisado (1957, 1978 e 2002), foram elaborados mapas de uso e cobertura do solo na escala 1:50.000.

Os critérios da legislação ambiental mapeados referem-se às Áreas de Preservação Permanente (APP), seguindo o disposto no Código Florestal (Lei $\left.n^{\circ} 4.771 / 1965\right)$ e na Resolução do CONAMA ${ }^{\circ}$ 303/2002. Foram mapeadas as APPs dos rios tributários e do rio principal (Rio Sete), das nascentes, das áreas com declividade acima de 45 graus e dos topos de morro.

\section{Entrevistas estruturadas}

Além dos dados gerados a partir dos mapas de uso e cobertura do solo, também foram aplicados questionários com agricultores e representantes de diferentes setores de interesse com atuação no município de São Bonifácio. A identificação dos participantes da pesquisa (entrevistados) foi feita a partir de reuniões realizadas com as famílias integrantes do Projeto Microbacias $2^{3}$ no município e a disponibilidade e interesse delas em participar da pesquisa. Os questionários tinham como principal objetivo identificar os conflitos entre agricultores familiares e a legislação ambiental.

Foram entrevistadas 21 famílias de agricultores familiares, um representante da EPAGRI (Empresa de Pesquisa Agropecuária e Extensão Rural de Santa Catarina) do município de São Bonifácio, o secretário de agricultura do município e um representante da Polícia de Proteção Ambiental, responsável pela fiscalização ambiental da região da Grande Florianópolis (integra o município de São Bonifácio).

\section{RESULTADOS E DISCUSSÃO}

\section{As Áreas de Preservação Permanente da microbacia do Rio Sete - São Bonifácio}

As Áreas de Preservação Permanente totalizam $26,2 \%$ da microbacia (MB) do Rio Sete, ocupando 1.563,40 hectares de extensão. As APPs de topos de morro e dos rios tributários são as que ocupam a maior área, correspondendo a $12 \%$ e $10 \%$ da MB, respectivamente (Tabela 1) (Figura 2).

Tabela 1. Área total das categorias de área de preservação permanente na MB do Rio Sete.

Table 1. Total area of the permanent preservation areas' categories in the Rio Sete microbasin.

\begin{tabular}{lcc}
\hline \multirow{2}{*}{ Categorias de APP } & \multicolumn{2}{c}{ Área total de APPs } \\
\cline { 2 - 3 } & $\boldsymbol{\%}$ & hectares \\
\hline Topo de Morro & 12,2 & 727 \\
Nascentes & 1,2 & 71 \\
Mata ciliar dos rios tributários & 10,3 & 618 \\
Mata ciliar do rio principal & 2,3 & 138 \\
Declividade $\left(>45^{\circ}\right)$ & 0,2 & 9,4 \\
\hline Área total de APPs na MB do Rio Sete & 26,2 & $1.563,4$ \\
\hline
\end{tabular}

Com exceção das APPs de rios (sejam tributários ou o rio principal), todas as outras categorias de APP possuem mais da metade de suas áreas cobertas por vegetação, com diferentes estágios sucessionais. As APPs de declividade e de nascentes são as que apresentam a maior parte de sua extensão preservada, com $80,6 \%$ e $69,8 \%$ de cobertura vegetal nativa, respectivamente (Tabela 2).

\footnotetext{
${ }^{3}$ O Projeto Microbacias 2 faz parte do Programa de Recuperação Ambiental e Apoio ao Pequeno Produtor Rural, desenvolvido com recursos do Governo do Estado de Santa Catarina e do Banco Mundial.
} 


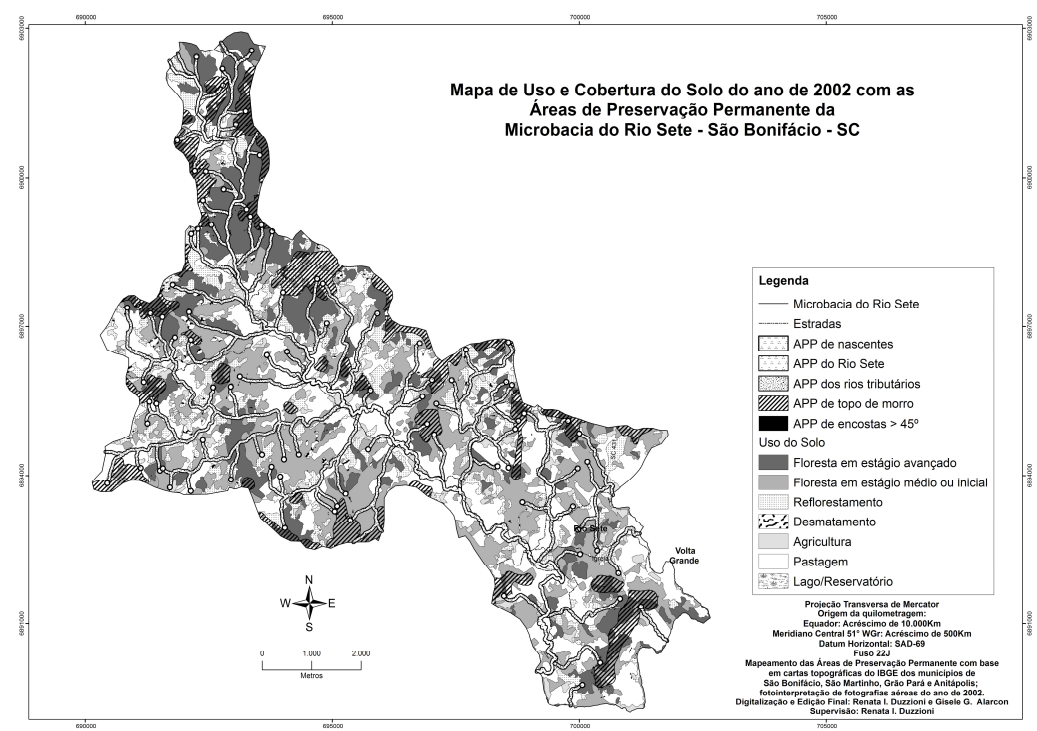

Figura 2. Mapa de uso e cobertura do solo da MB do Rio Sete do ano de 2002, com as áreas de preservação permanente.

Figure 2. Rio Sete microbasin land use and vegetation cover map in the year 2002, with the permanent preservation areas.

Tabela 2. Categorias de uso e cobertura do solo nas áreas de preservação permanente da MB do Rio Sete em 2002.

Table 2. Land use and vegetation cover categories in the permanent preservation areas in the Rio Sete microbasin in 2002.

\begin{tabular}{|c|c|c|c|c|c|c|c|c|c|c|}
\hline \multirow{3}{*}{$\begin{array}{l}\text { Categorias de uso } \\
\text { e cobertura do } \\
\text { solo }\end{array}$} & \multicolumn{10}{|c|}{ Categorias de APP } \\
\hline & \multicolumn{2}{|c|}{ Topo de morro } & \multicolumn{2}{|c|}{ Nascentes } & \multicolumn{2}{|c|}{$\begin{array}{l}\text { Mata ciliar } \\
\text { rios tributários }\end{array}$} & \multicolumn{2}{|c|}{$\begin{array}{c}\text { Mata ciliar rio } \\
\text { principal }\end{array}$} & \multicolumn{2}{|c|}{$\begin{array}{c}\text { Declividade } \\
\left(>45^{\circ}\right)\end{array}$} \\
\hline & $\%$ & ha & $\%$ & ha & $\%$ & ha & $\%$ & ha & $\%$ & ha \\
\hline Agricultura & 2,9 & 21 & 1,4 & 1 & 3 & 22 & 7 & 10 & 0,7 & 0,06 \\
\hline Solo descoberto & 1,5 & 11 & 1,5 & 1 & 1 & 4 & 0 & 0 & 0,2 & 0,01 \\
\hline $\begin{array}{l}\text { Floresta primária } \\
\text { ou em estágio } \\
\text { avançado }\end{array}$ & 33,3 & 242 & 32,0 & 23 & 20 & 124 & 12 & 16 & 33,3 & 3,1 \\
\hline $\begin{array}{l}\text { Floresta em estágio } \\
\text { médio ou inicial }^{4}\end{array}$ & 26,6 & 193 & 37,8 & 27 & 25 & 152 & 10 & 13 & 47,3 & 4,5 \\
\hline Pastagem & 16,5 & 120 & 10,1 & 7 & 40 & 249 & 61 & 84 & 10,5 & 1 \\
\hline $\begin{array}{l}\text { Reflorestamento } \\
\text { com exóticas }\end{array}$ & 19,2 & 140 & 17,2 & 12 & 11 & 67 & 10 & 14 & 8,2 & 0,8 \\
\hline Área total & 100 & 727 & 100 & 71 & 100 & 618 & 100 & 138 & 100 & 9,4 \\
\hline
\end{tabular}

A evolução dos tipos de uso e cobertura do solo nas APPs aponta uma redução das áreas de agricultura, de floresta primária ou em estágio avançado e de floresta em estágio médio ou inicial nas APPs, entre as décadas de 1950 e 2000. Em contrapartida, verifica-se o aumento das áreas de pastagem (maior categoria de uso do solo da microbacia em 2002 em APPs) e de reflorestamento com espécies exóticas (Figura 3). Essas atividades econômicas (pecuária e produção madeireira) respondem às demandas dos mercados locais e regionais e representam um percentual significativo da renda do município.

\footnotetext{
${ }^{4}$ Os estágios sucessionais considerados para fins deste trabalho consideram as características fisionômicas estabelecidas pela Resolução do CONAMA n 04, de 1994, que define os estágios sucessionais das formações florestais do bioma Mata Atlântica para Santa Catarina. Segundo o artigo $2^{\circ}$ da referida Resolução, a vegetação secundária ou em regeneração é aquela resultante dos processos naturais de sucessão, após supressão total ou parcial da vegetação primária por ações antrópicas ou causas naturais, podendo ocorrer árvores remanescentes da vegetação primária.
} 


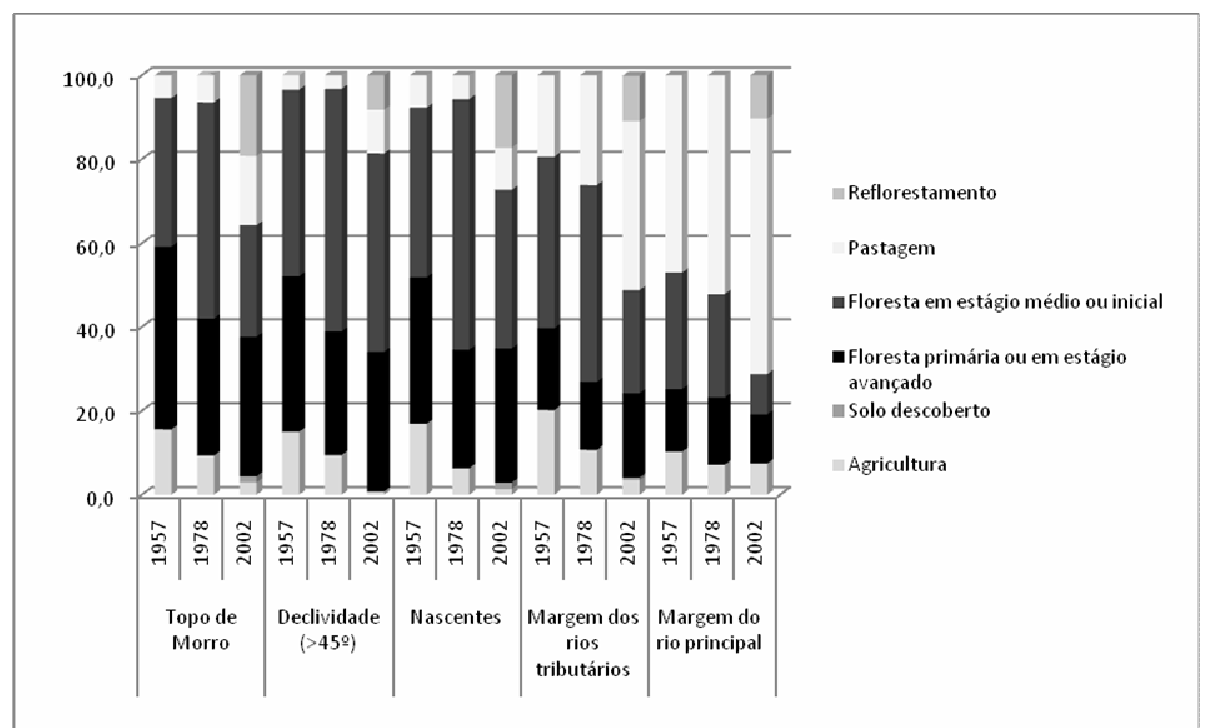

Figura 3. Evolução das categorias de uso e cobertura do solo nas APPs da MB do Rio Sete nos anos de 1957,1978 e 2002.

Figure 3. Land use and vegetation cover categories changes in the Rio Sete microbasin permanent preservation areas. 1957, 1978 and 2002.

No caso das APPs de topos de morro, a expansão da pastagem e do reflorestamento foi principalmente sobre a floresta em estágio médio ou inicial e, secundariamente, sobre as áreas abandonadas de agricultura. Entre os anos de 1957 e 1978, a floresta em estágio médio ou inicial aumentou $16 \%$ nos topos de morro, entretanto nas décadas seguintes registrou o declínio de $16 \%$, retornando à condição da década de 1950.

O uso mais intensivo dos topos de morro na década de 1950 está associado à prática da agricultura itinerante, quando os topos de morro eram utilizados rotativamente como áreas produtivas. Já na década de 1970 a agricultura reduziu-se 6,3\% nessa APP. Esse fato está relacionado à introdução das práticas da terra lavrada, que interferiu diretamente na recuperação das florestas em estágio médio ou inicial nos topos de morro e em toda a microbacia (ALARCON, et al., 2008). Por outro lado, entre 1978 e 2002, os topos de morro perdem novamente as áreas de floresta em estágio médio ou inicial (16\%), que dão lugar à pastagem e ao reflorestamento, que passou a ocupar 19,2\% das APPs de topos de morro.

Apesar de proibido, o estabelecimento de reflorestamentos nos topos de morro constitui uma estratégia produtiva dos agricultores, uma vez que essa atividade não exige o manejo constante. Como os topos de morro normalmente são áreas de difícil acesso, principalmente nessa região, o reflorestamento permite a geração de renda em parte da unidade produtiva, sem comprometer outras áreas normalmente ocupadas para outras atividades produtivas, que exigem o manejo constante, como a agricultura e a pecuária leiteira.

As APPs de topos de morro são de difícil delimitação, o que contribui para o uso inadequado dos solos nesses locais (COSTA et al., 1996; RIBEIRO et al., 2005). Segundo os autores, existe uma visível dificuldade em materializar, mesmo em termos de mapeamento, as APPs em topos de morro, montanhas e linhas de cumeada. Essa dificuldade abre precedentes nos próprios órgãos de fiscalização ambiental e, muitas vezes, exige um extenso trabalho de campo, complementado pelo trabalho de mapeamento, para a delimitação dessas APPs. Se existe dificuldade por parte dos órgãos ambientais em delimitar as APPs de topos de morro, a situação para o pequeno agricultor deve ser ainda mais complicada, já que ele não dispõe das mesmas ferramentas e do mesmo conhecimento técnico.

Assim como nas APPs de topos de morro, nas APPs de nascentes e floresta em estágio médio ou inicial sofreu um aumento de $19 \%$, entre 1957 e 1978, e um declínio de $22 \%$ entre 1978 e 2002 . A agricultura, por sua vez, sofreu um declínio constante nas APPs de nascentes entre 1957 e 2002 (15,5\%). A floresta primária ou em estágio avançado também diminuiu e representava, em 2002, 32\% das APPs de 
nascentes. As atividades que aumentaram nas APPs de nascentes foram a pecuária (cresceu 2,4\%) e o reflorestamento (cresceu 17\%).

A flutuação das florestas em estágio médio ou inicial nas APPs de nascentes, entre 1957 e 2002, está relacionada ao mesmo fato apontado para a flutuação das florestas nas APPs de topos de morro. Com o surgimento da terra lavrada na década de 1970, a área utilizada para agricultura itinerante diminuiu, o que permitiu a regeneração da floresta em estágio médio ou inicial. Entretanto, nas décadas seguintes, o aumento das áreas de pastagem e o surgimento do reflorestamento acarretam o uso das áreas onde a floresta encontrava-se em regeneração.

Por outro lado, merece destaque o fato de que as APPs de nascentes estão, em sua maioria, protegidas, visto que, somadas as florestas primária e em estágio avançado com as florestas em estágio médio ou inicial de regeneração, $70 \%$ das APPs de nascentes estão protegidas pela vegetação nativa.

Com relação às APPs de encosta, é possível verificar o declínio da agricultura, que ocupava $15 \%$ delas em 1957, e passou a ocupar 0,7\% em 2002 (denota o maior declínio entre as atividades produtivas nas APPs). A presença da agricultura em áreas com declividade superior a $45^{\circ}$, na década de 1950 , está relacionada à agricultura itinerante, em que a rotatividade das áreas de plantio implicava também o uso das áreas mais íngremes. Nas décadas seguintes, essas APPs sofreram um aumento de áreas convertidas em pastagem (cresceu 7,1\% entre 1957 e 2002) e em reflorestamento (cresceu 8,2\% entre 1957 e 2002). Com o surgimento da terra lavrada e a expansão da pecuária e do reflorestamento, a agricultura deixou de ser uma atividade produtiva significativa nas propriedades, o que se acentuou principalmente nas áreas com declividade superior a $45^{\circ}$. Esse fato provavelmente está relacionado à dificuldade do acesso a essas áreas, o que levou à substituição por outras atividades produtivas (pastagem e reflorestamento) que exigissem menos manutenção.

Cabe chamar a atenção para o fato de que as APPs de encosta (declividade acima de $45^{\circ}$ ) são as que se encontram com o maior grau de proteção, com $80,6 \%$ de suas áreas recobertas por floresta primária ou em estágio avançado (33,3\%) e por floresta em estágio médio ou inicial $(47,3 \%)$. Se comparada com a década de 1950, as áreas dessas APPs com floresta primária ou em estágio avançado diminuíram 5\%, enquanto as áreas com floresta em estágio médio ou inicial aumentaram 3\%. Nesse sentido, o que se percebe é que não houve uma variação significativa nas áreas com declividade superior a $45^{\circ}$. A expansão da pecuária e do reflorestamento deu-se principalmente sobre as áreas de agricultura que foram abandonadas e, secundariamente, sobre as áreas de floresta primária ou em estágio avançado.

Quanto às APPs de mata ciliar, é possível notar diferença entre a intensidade de uso das APPs dos rios tributários e as APPs do Rio Sete (rio principal). Nas APPs dos rios tributários, assim como nas APPs de topos de morro e nascentes, a agricultura sofreu um declínio significativo $(16,7 \%)$ entre 1957 e 2002. Do mesmo modo, também diminuíram as APPs com floresta em estágio médio ou inicial, que deixaram de representar 40,6\% das APPs dos rios tributários em 1957 para representar 24,6\% em 2002. Já o reflorestamento cresceu $10,8 \%$, e a pastagem $21 \%$, constituindo a categoria de uso com maior crescimento nas APPs dos rios tributários (Figura 3).

Com relação às APPs do Rio Sete, as florestas em estágio médio ou inicial reduziram-se 18\%, entre 1957 e 2002. Já as áreas com floresta primária ou em estágio avançado e agricultura não tiveram muita transformação entre 1957 e 2002 , reduzindo $3,2 \%$ e 2,4\%, respectivamente. O reflorestamento cresceu, representando, em 2002, 10,3\% das APPs das margens do Rio Sete. Quanto à pastagem, verificase que esse uso já representava uma área significativa (47\%) nas APPs em 1957, e sua expansão ficou um pouco abaixo (14\%) da expansão observada nas APPs dos rios tributários. Esse fato está relacionado ao processo de ocupação do município: as primeiras famílias consolidavam-se sempre às margens dos rios principais e, quando essas áreas encontravam-se ocupadas, partiam para as áreas mais altas e distantes (SCHADEN, 1940). Nesse sentido, o crescimento da pastagem nas margens dos rios tributários está relacionado à expansão dessa atividade produtiva para as áreas mais remotas da microbacia, as quais se dedicavam anteriormente à agricultura, sendo esta a principal atividade de uso do solo nas APPs dos rios tributários em 1957.

A expansão da pastagem associada ao crescimento da pecuária no município entre os anos $50 \mathrm{e}$ 2000, mostra que essa atividade substituiu as áreas de agricultura e invadiu as áreas de floresta em estágio médio ou inicial e de floresta primária ou em estágio avançado, inclusive nas APPs, desrespeitando as determinações do Código Florestal de 1965. 


\section{A percepção dos atores sociais envolvidos}

Os conflitos levantados pelos agricultores participantes da pesquisa com relação à aplicação das leis ambientais são diversos e estão relacionados principalmente à dificuldade de implementação dos critérios da legislação ambiental (através das APPs) nas propriedades dos pequenos produtores de São Bonifácio. Esse fato se agrava devido às características do município, que se encontra numa área bastante montanhosa, abundante em recursos hídricos e com importantes remanescentes do bioma Mata Atlântica (Tabela 3).

Tabela 3. Percepções das famílias dos agricultores entrevistadas acerca da legislação ambiental.

Table 3. Perceptions of the agriculturists' families interviewed about the environmental legislation.

\begin{tabular}{|c|c|}
\hline \multicolumn{2}{|r|}{ Análise da legislação ambiental } \\
\hline Categorias de análise & Respostas e frequência* \\
\hline Não é adequada. & $\begin{array}{l}\text { "na região não é bom não, porque tem muitos rios", "não sobra área pra plantá", "deveria } \\
\text { ter leis estaduais", "se for cumprir a lei à risca não tem como usar a propriedade dos } \\
\text { pequenos agricultores (4)", "é importante em outros locais, nas condições de São } \\
\text { Bonifácio não dá (2)", "as leis dos riozinhos pequenos estão erradas". }\end{array}$ \\
\hline $\begin{array}{l}\text { Não funciona igual } \\
\text { para todos. }\end{array}$ & $\begin{array}{l}\text { "quem tem dinheiro e pode pagar plano de corte pode derrubá, quem não tem, não pode } \\
\text { (5)". }\end{array}$ \\
\hline É importante. & $\begin{array}{l}\text { "tem sua vantagem, não dá pra destruir toda a água", "é certo deixar a mata na beira do } \\
\text { rio (4)". }\end{array}$ \\
\hline
\end{tabular}

*Os números entre parênteses representam o número de famílias que repetiram as frases.

A dificuldade de aplicação das leis ambientais em São Bonifácio também foi destacada pelo técnico da EPAGRI do município, ao afirmar:

[...] Os parâmetros para realidade local de pequenas propriedades e relevo montanhoso não devem ser os mesmos na legislação de áreas como o Brasil central $[\ldots]$.

Essas questões constituem atualmente um grande impasse, principalmente em áreas de Mata Atlântica, onde predomina a pequena propriedade rural. De um lado, afincam-se os conservacionistas, que lutam pela preservação dos remanescentes de Mata Atlântica; de outro, os extencionistas e produtores rurais, que apontam a inviabilidade econômica das pequenas propriedades em áreas de Mata Atlântica, se aplicadas as normas da legislação ambiental.

Para Trentini (2004), a legislação ambiental é vista pela maior parte dos pequenos produtores rurais como uma tarefa a ser cumprida e que pode significar prejuízos econômicos a sua atividade. A autora assinala que as restrições às práticas agrícolas decorrentes da legislação ambiental parecem ter ocasionado a diminuição dos rendimentos econômicos dos pequenos produtores rurais.

Nesse mesmo sentido, o secretário de agricultura de São Bonifácio destaca:

[...] nos casos em que realmente for comprovada que a propriedade é inviável para exploração agropecuária, que se tomem as medidas necessárias para viabilizar a vida desta família, já que ela não pode arcar com os custos da preservação ambiental isoladamente [...].

A indenização do proprietário rural, quando ocorre o esvaziamento do conteúdo econômico da propriedade em função de uma limitação administrativa (no caso, a legislação ambiental), é assegurada por lei (MACHADO, 2000; BRASILEIRO BORGES, 1999). No entanto, cabe destacar algumas limitações relacionadas a esse fato: os critérios da legislação ambiental não são respeitados, historicamente, pelos pequenos produtores rurais. As alternativas de uso da terra, inclusive em APPs e reserva legal, não são conhecidas pelos pequenos agricultores, e eles não possuem o apoio institucional devido para sua implementação. Considerando-se que os órgãos ambientais mal conseguem implementar um programa de fiscalização ambiental efetivo (com propostas, além de coibitivas, informativas), como fará a avaliação para verificar o esvaziamento do conteúdo econômico das propriedades?

Além dos conflitos relacionados ao esvaziamento do conteúdo econômico das pequenas propriedades rurais, outro conflito que vem a lume, quando discutidas as relações entre as leis ambientais e os pequenos produtores rurais em áreas de Mata Atlântica, é a implementação da fiscalização ambiental em si. 
De acordo com Neumann; Loch (2002), a Política Nacional de Meio Ambiente (Lei n ${ }^{\circ} 6.938$, de 1981) prevê três categorias de instrumentos de gestão ambiental: instrumentos regulatórios e punitivos, instrumentos de mercado ou incentivos econômicos e instrumentos de informação. Entretanto, apesar de dispor desses três instrumentos de gestão, a legislação ambiental tem sido implementada, de fato, através de instrumentos de controle e punição.

Em São Bonifácio, as famílias de agricultores entrevistadas destacaram os principais pontos negativos e positivos com relação à fiscalização ambiental (Tabela 4).

Tabela 4. Aspectos positivos e negativos destacados pelas famílias de agricultores entrevistadas com relação à fiscalização ambiental.

Table 4. Positive and negative aspects detached by the agriculturists' families interviewed about the environmental fiscalization.

\begin{tabular}{ll}
\hline Aspectos positivos & Aspectos negativos \\
\hline (7) impede as derrubadas. & (2) é violenta e desrespeita o agricultor. \\
(3) ajudam a cuidar da água. & (4) impede a retirada da madeira. \\
(1) dissemina informação. & (3) multa os pequenos produtores. \\
& (5) favorece alguns (com pagamento de corte). \\
& (2) não é informativa. \\
\hline
\end{tabular}

* Os números entre parênteses indicam o número de famílias que mencionaram o mesmo aspecto.

O aspecto mencionado com maior frequência entre as famílias foi um fator positivo da fiscalização, devido ao fato dela impedir as grandes derrubadas. Três famílias afirmaram que a fiscalização ajuda a cuidar da água, e apenas uma apontou a disseminação de informações como um fator positivo da fiscalização.

No que se refere aos aspectos negativos, alguns pontos se contrapõem aos pontos positivos levantados, tais como a proibição da retirada de madeira e o fato da fiscalização não ser informativa. Em alguns depoimentos, percebe-se um confronto de valores entre a fiscalização ambiental adotada e os benefícios e malefícios junto à comunidade.

[..] a fiscalização não é boa, mas numa parte é importante, porque se não tiver fiscalização, ninguém respeita mais [...].

[...] eles ficam em cima, se a fiscalização não viesse eles continuavam a derrubá tudo [...].

Ao mesmo tempo em que a fiscalização atrapalha as atividades dos agricultores, ela também condiciona suas ações, de forma a gerar alguns benefícios (preservação da água, evitar grandes derrubadas) para a própria comunidade.

O "favorecimento" de alguns proprietários em detrimento de outros foi apontado por cinco famílias, e também foi destacado pelo técnico coordenador do Projeto Microbacias 2 da EPAGRI de São Bonifácio, como segue:

[...] "Há propriedades extensas aqui em São Bonifácio que a polícia não autua, porque devem ser de "peixe grande". No entanto, penaliza agricultores que impactam áreas de menos de 1 ha e que o fazem para manter a subsistência da família tão somente" [...].

O secretário da agricultura de São Bonifácio também fez observações nessa mesma direção:

[...] "O que se observa é que se o produtor tem condições financeiras para realizar e pagar os trâmites legais exigidos, ele consegue as autorizações. Porém, mesmo que ele proceda de acordo com a preservação do meio ambiente, mas não tenha recursos para pagar as taxas ou os técnicos exigidos, ele é considerado um contraventor" [...].

Em contrapartida, segundo o capitão da Polícia de Proteção Ambiental entrevistado, o procedimento de infrações e multas é aplicado igualmente entre os infratores, sejam pequenos, médios ou grandes produtores. Ademais, o capitão destacou que a Polícia Ambiental desenvolve atividades preventivas, as quais se materializam através de rondas periódicas e palestras esporádicas nos municípios.

A licença para corte foi um procedimento adotado a partir do Código Florestal, mas foi regulamentada posteriormente, através da Resolução do CONAMA n 237, de 1997. Na Mata Atlântica, o 
Decreto $n^{\circ}$ 750, de 1993, a Resolução do CONAMA 04, de 19945, a Resolução do CONAMA 261, de 1999, e, posteriormente, a Lei da Mata Atlântica (Lei $\mathrm{n}^{\circ} 11.428$, de 2006), que revoga o Decreto ${ }^{\circ}$ 750/93, são os instrumentos jurídicos que orientam o processo de licenciamento de corte da vegetação nativa para o uso agropecuário ${ }^{6}$. Entretanto, cabe destacar que, em Santa Catarina, os licenciamentos de corte florestal foram motivo de uma ação civil pública (AC n ${ }^{\circ}$ 96.04.43429-2/SC) movida pelo Ministério Público contra a FATMA, em 1993 (HARTMAN, 2001). Segundo a autora, existem controvérsias na área ambiental na esfera dos governos estaduais e federal, o que dificulta a implementação das leis. Em seu estudo, a autora destaca que um representante do IBAMA (Instituto Brasileiro do Meio Ambiente e dos Recursos Naturais Renováveis) de Santa Catarina afirmou que um pacto federativo com os órgãos estaduais de gestão ambiental não funcionaria, visto que "as fundações estaduais funcionam muito mal e até contra a lei". Nesse contexto, o pequeno produtor rural acaba ficando a mercê das políticas implementadas em escala muito distante, sem muita opção de contar com a esfera política local no que tange às particularidades de uso do solo e exploração dos recursos naturais.

Quando questionados sobre possíveis mudanças na legislação ambiental, os agricultores destacaram dois fatores principais: a regionalização ou municipalização das leis ambientais e a redução da metragem das matas ciliares (Tabela 5).

Tabela 5. Mudanças sugeridas pelas famílias de agricultores entrevistadas quanto à legislação ambiental.

Table 5. Changes suggested by the agriculturists' families interviewed about the environmental legislation.

(4) Legislação deveria ser regionalizada ou municipalizada.

(4) Reduzir metragem de mata ciliar (APP) para pequenos produtores.

(3) Estabelecimento de um percentual de APP para as propriedades e liberar o uso do restante.

(2) Rever diâmetro de corte da capoeira ${ }^{7}$.

(2) Rever pagamento para plano de corte.

(1) Orientação sobre a legislação ambiental para produtores rurais.

(1) Subsídio para pequenos produtores rurais pela conservação da floresta.

(1) Liberação do corte de madeira nativa de crescimento rápido.

(1) Obrigatoriedade de recuperação em propriedades sem mata.

* Os números entre parênteses indicam o número de famílias que mencionaram o mesmo aspecto.

Neumann; Loch (2002) e Bley Júnior et al. (2004) questionam os critérios adotados para a delimitação das metragens atribuídas às APPs e às Reservas Legais. Algumas iniciativas do bloco parlamentar, que defende os interesses dos grandes produtores rurais (conhecido como "bloco ruralista"), ao longo dos últimos 20 anos, vêm tentando modificar o Código Florestal, principalmente no que se refere às APPs e Reservas Legais. Dentre essas iniciativas, destaca-se a proposta da Medida Provisória ${ }^{\circ}$ 1.956, de 2000, que introduz alterações nos limites ao redor de reservatórios, remete à legislação municipal as APPs em áreas urbanas, propõe a redução dos percentuais de Reserva Legal, a possibilidade de cômputo de espécies exóticas e não aborda a necessidade de recomposição da vegetação (JURAS; ARAÚJO, 2000).

Em Santa Catarina, a Lei Estadual n 14.675/2009, que estabelece o Código Ambiental do Meio Ambiente, instituiu novas metragens para a faixa de APPs para propriedades abaixo e acima de 50 hectares, as quais passam a atingir a largura máxima de 10 metros (em ambos os casos) acrescidos de $50 \%$ da medida excedente a 10 metros para os cursos d'água com largura superior a 10 metros, reduz as APPs de nascentes para 10 metros, além de outros dispositivos menos restritivos que a legislação federal que trata do assunto (SANTA CATARINA, 2009). Embora a lei tenha sido sancionada em abril de 2009,

\footnotetext{
${ }^{5}$ A Resolução do CONAMA n ${ }^{\circ}$ 04, de 1994, dispõe sobre os critérios para a classificação dos estágios sucessionais das formações florestais do bioma Mata Atlântica (Floresta Ombrófila Densa, Floresta Ombrófila Mista e Floresta Estacional Decidual) em Santa Catarina.

${ }^{6}$ Com a promulgação da Lei da Mata Atlântica (Lei n ${ }^{\circ} 11.428$, de 2006), o Decreto ${ }^{\circ} 750$ deixa de ter validade, permanecendo apenas as resoluções do CONAMA promulgadas posteriormente ao Decreto nos estados da federação, com relação aos critérios de categorização dos estágios sucessionais das formações florestais do bioma Mata Atlântica.

${ }^{7}$ A "capoeira" é um termo utilizado para os estágios sucessionais da floresta, sendo que, neste caso, refere-se a um estágio médio de regeneração da Floresta Ombrófila Densa.
} 
em junho do mesmo ano foi ajuizada pelo Procurador Geral da República uma Ação Direta de Inconstitucionalidade, com pedido de medida cautelar, para questionar o Código Estadual do Meio Ambiente de Santa Catarina (SUPREMO TRIBUNAL FEDERAL, 2009).

Essas iniciativas são destacadas por Fearnside (2000) como medidas que visam apenas resolver o interesse dos grandes proprietários, possibilitando lucro maior às grandes propriedades e uma perda completa, em termos de florestas e biodiversidade, para a nação brasileira.

Como destacado por Alceo Magnani (URBAN, 1998), houve muita discussão, durante a elaboração do Código Florestal de 1965, sobre a homogeneização dos números e percentuais das APPs, contudo, como ele mesmo destaca, "era impossível contemplar todas as condicionantes locais em uma lei e era preciso preservar aquilo que restava". Segundo Ahrens (2003), a despeito do frequente descumprimento dos dispositivos do Código Florestal, essa lei foi essencial para proteger o que resta da cobertura florística brasileira. Ademais, possibilidades de uso e flexibilização em casos específicos vêm sendo incorporadas através de novas leis e outros tipos de normatizações, principalmente a partir dos anos 90 .

Três famílias sugeriram o estabelecimento de uma porcentagem específica de APP e a liberação de uso do restante da propriedade. Essa proposta nos remete a duas questões importantes. A primeira delas é a função das APPs, que podem ou não totalizar uma área significativa da propriedade. Ao proteger as margens de rios, nascentes, encostas e topos de morro, a lei nada mais faz do que auxiliar o proprietário na manutenção da qualidade dos recursos hídricos e da fertilidade do solo em sua propriedade. Isso quer dizer que o percentual das APPs deve ser fundamentalmente garantido como espaço verde com floresta nativa, já que protege a propriedade e garante a sua manutenção. Outro fator importante é a possibilidade de uso da Reserva Legal. Embora cinco famílias reconhecessem a Reserva Legal como um dos critérios das leis ambientais e, dentre as entrevistadas, dez possuem uma área de reserva florestal (não averbada) em suas propriedades, os agricultores desconhecem as possibilidades de uso que a categoria reserva florestal permite.

A Medida Provisória (MP) n 2.166, de 2001, prevê que a vegetação da Reserva Legal não pode ser suprimida, mas pode ser utilizada sob regime de manejo florestal sustentável. E, no caso de pequenos produtores rurais, para o cumprimento da manutenção ou compensação da área de Reserva Legal, "podem ser computados os plantios de árvores frutíferas ornamentais ou industriais, compostos por espécies exóticas, cultivadas em sistema intercalar ou em consórcio com espécies nativas" (BRASIL, 2001). Nesse sentido, os parágrafos $2^{\circ}$ e $3^{\circ}$ do artigo 16 , da MP $\mathrm{n}^{\circ} 2.166 / 2001$, asseguram aos pequenos produtores rurais um tratamento diferenciado, no intuito de evitar que haja o esvaziamento do conteúdo econômico de sua propriedade e que a preservação restrita das florestas fundamente-se no percentual das APPs (embora algumas exceções também sejam dadas aos pequenos produtores rurais).

Apenas uma família mencionou a possibilidade de subsídios para os agricultores com a manutenção das florestas em suas propriedades. Entretanto os subsídios mencionados pela família entrevistada significariam manter a família na unidade produtiva, explorando dentro do que preveem as leis ambientais e, em função do esvaziamento parcial do conteúdo econômico da propriedade, criar benefícios financeiros que permitissem à família permanecer em sua propriedade. Esses benefícios complementariam a renda que seria obtida caso a propriedade estivesse convertida em atividades agrícolas.

Subsídios para a manutenção da pequena propriedade no campo e para a conservação dos recursos naturais dessas propriedades são, de fato, legítimos. Embora não haja uma legislação nacional regulamentando a matéria, há algumas iniciativas estaduais de subsídios a pequenos produtores rurais que desenvolvem práticas de uso do solo mais compatíveis com a conservação dos recursos naturais. Dentre essas iniciativas estão as do estado do Amazonas e Minas Gerais, que lançaram o Programa Bolsa Verde, cujos objetivos são instituir o pagamento por serviços e produtos ambientais às comunidades tradicionais pelo uso sustentável dos recursos naturais, conservação, proteção ambiental e incentivo às políticas voluntárias de redução de desmatamento. Não obstante, é importante considerar as possibilidades de usos permitidos aos pequenos produtores rurais, através das próprias leis ambientais, antes de viabilizar subsídios às propriedades.

As possibilidades de uso e exploração dos recursos naturais na pequena propriedade rural começaram a se materializar nas leis ambientais (mesmo que pontualmente) principalmente a partir dos anos 90 , como resultado do processo de mobilização da sociedade no debate sobre a conservação dos recursos naturais e a sustentabilidade no meio rural. 
Uma dessas possibilidades foi mencionada anteriormente e refere-se ao manejo sustentável das áreas de Reserva Legal e a possibilidade de consorciamento de espécies frutíferas e/ou exóticas com espécies nativas (MP $n^{\circ} 2.166$, de 2001). Ainda nessa MP, no artigo $n^{\circ} 16$, fica permitido em pequenas propriedades rurais o cômputo das áreas de vegetação nativa existentes em APP no cálculo do percentual de Reserva Legal, desde que não implique conversão de novas áreas para o uso alternativo do solo e quando a soma da vegetação nativa em Área de Preservação Permanente e Reserva Legal exceder a vinte e cinco por cento da pequena propriedade rural. Ademais, a MP garante a gratuidade para o pequeno produtor rural na averbação da Reserva Legal e assegura o apoio técnico e jurídico para esse segmento social.

As normas da MP $\mathrm{n}^{\circ} 2.166$, de 2001, buscaram diferenciar o tratamento dado pelo Código Florestal ao pequeno produtor rural e resolvem, em grande parte, o problema do esvaziamento do conteúdo econômico da pequena propriedade.

A Resolução do CONAMA $n^{\circ} 369$, de 2006, também traz algumas possibilidades específicas para o pequeno produtor rural. Segundo essa resolução, ficam permitidas a exploração eventual e de baixo impacto e atividades de manejo agroflorestal sustentável em APPs nas propriedades de pequenos produtores rurais, desde que a atividade abranja até 5\% da APP impactada na propriedade. Essa resolução busca aumentar as áreas de uso da terra nas pequenas propriedades rurais, inclusive nas Áreas de Preservação Permanente.

Além da Resolução n 369/2006, a Lei da Mata Atlântica (Lei n 11.428) também busca avanços no sentido de viabilizar a exploração racional dos recursos naturais nas pequenas propriedades rurais. Em seu Artigo $\mathrm{n}^{\circ}$ 9, por exemplo, a lei dispensa o pedido de autorização para a exploração eventual de espécies da flora nativa para consumo das propriedades de pequenos produtores rurais. Também permite a exploração da vegetação em estágio médio de regeneração para atividades imprescindíveis à subsistência da pequena propriedade rural, ressalvadas as APPs e mediante a averbação da Reserva Legal.

As normas adotadas a partir da Lei da Mata Atlântica buscam regulamentar o uso da floresta em estágio médio ou inicial para pequenos agricultores, conforme definido anteriormente pelo Decreto ${ }^{\circ}$ 750, de 1993. Outro aspecto bastante importante que torna a categoria "pequeno produtor rural" diferente a partir da instituição da Lei da Mata Atlântica é a definição do pequeno produtor rural para fins da legislação ambiental. Até a MP no 2.166, de 2001, a pequena propriedade rural "era aquela explorada mediante o trabalho pessoal do proprietário ou posseiro e de sua família, admitida a ajuda eventual de terceiro e cuja renda bruta seja proveniente, no mínimo, em oitenta por cento, de atividade agroflorestal ou do extrativismo, cuja área não supere 30 hectares (para a região da Mata Atlântica), ressalvadas as diferentes regiões". Com a Lei da Mata Atlântica, as definições da pequena propriedade rural permanecem, mas muda o tamanho da propriedade, sendo que a posse da gleba rural do pequeno produtor rural passa a ser considerada de até 50 hectares.

Também merece destaque a Lei Federal $n^{\circ} 11.284$, de 2006, que estabelece o Fundo Nacional de Desenvolvimento Florestal (FNDF), destinado a "fomentar o desenvolvimento de atividades sustentáveis de base florestal no Brasil e promover a inovação tecnológica do setor". Os recursos do FNDF serão destinados a projetos de órgãos e entidades públicas ou de entidades privadas sem fins lucrativos. Os recursos serão geridos por um conselho consultivo e deverão ser aplicados prioritariamente em projetos de extensão rural e florestal, educação ambiental, capacitação em manejo florestal, monitoramento e recuperação de áreas degradadas, dentre outros. Essa lei também prevê uma série de políticas públicas que visam ordenar a exploração das florestas públicas brasileiras. O FNDF poderá contribuir diretamente com ações junto aos pequenos produtores e agricultores familiares no que tange aos itens mencionados acima.

No meio rural, esses fatos (ou a ausência deles) acarretam na quase total inexistência de divulgação das leis ambientais e suas possibilidades, na indisposição dos pequenos produtores junto aos órgãos de fiscalização e na baixa eficácia das atividades de fiscalização ambiental. Nesse último caso, a fiscalização tem um efeito coibitivo, que leva, em parte, à redução das atividades de desmatamento e extração de espécies de madeiras nobres da floresta, porém não postula a construção de conhecimento e não leva as alternativas possíveis aos pequenos agricultores, o que acaba por resultar na continuidade das ações de desmatamento em longo prazo.

Por fim, a falta de participação dos pequenos produtores rurais no processo de discussão sobre a legislação ambiental acaba por distanciá-los das normas legais e faz com que elas não atendam às características locais e regionais. 


\section{CONCLUSÕES}

- A despeito dos avanços significativos das leis ambientais, principalmente a partir dos anos 90, na microbacia do Rio Sete o uso do solo foi intensificado em todas as categorias de APP entre 1957 e 2002, o que demonstra que a implementação dessas leis foi pouco eficaz.

- As transformações ocorridas no uso e cobertura do solo nas APPs da microbacia do Rio Sete refletem os ciclos e tendências das atividades econômicas, principalmente em escala regional. O crescimento da pecuária leiteira e do reflorestamento direcionou a ocupação de novas áreas nas APPs a partir dos anos 80 , abrangendo grande parte das margens de rios (principalmente do rio principal) e os topos de morro. As leis ambientais serviram apenas como um fator inibidor do processo de desmatamento, mas não o reduziram por completo e não possibilitaram a recuperação de áreas degradadas e a criação de estratégias que permitissem que os pequenos produtores rurais integrassem a produtividade de suas propriedades à conservação dos recursos naturais. Sua implementação se deu principalmente através de práticas punitivas, que geraram uma série de conflitos, os quais se tornaram empecilhos à sua própria implementação.

- As leis ambientais promulgadas nos últimos dez anos têm avançado na direção da conservação dos remanescentes florestais da Mata Atlântica e têm considerado de maneira distinta o pequeno produtor rural. O problema reside no fato de que os órgãos ambientais sofrem com problemas estruturais, falta capacitação e aparelhamento, faltando, sobretudo, a integração efetiva entre os órgãos gestores das políticas de meio ambiente, os órgãos de extensão rural e o Ministério Público na implementação das leis.

- Embora a partir dos anos 1990 as leis ambientais tenham regulamentado exceções para pequenos produtores, a falta de conhecimento das alternativas propostas, sua efetiva implementação nas propriedades e a manutenção de uma política coibitiva têm gerado um cenário bastante negativo no meio rural, que se agrava em função da baixa participação desse segmento social nas discussões sobre a legislação ambiental em nível local.

- Neste sentido, é iminente que em conjunto com a regulamentação das leis ambientais, haja um amplo processo de debate e informação, a fim de que ocorra um manejo da paisagem, em que a floresta seja mantida, gerando renda, e os arranjos produtivos valorizem e integrem as espécies florestais nativas com as atividades agropecuárias.

\section{REFERÊNCIAS}

AHRENS, S. O novo Código Florestal Brasileiro: conceitos jurídicos fundamentais. Anais do VIII Congresso Florestal Brasileiro. São Paulo, 2003. Disponível em: www.ambientebrasil.com.br. Acessado em 25/02/2007.

ALARCON, G. G. Transformação da paisagem em São Bonifácio - SC: a interface entre a percepção de agricultores familiares, as práticas de uso do solo e aspectos da legislação ambiental. Dissertação de Mestrado, UFSC, Programa de Pós-Graduação em Geografia, Florianópolis, 2007.

ALARCON, G. G.; BELTRAME, A. V. da; KARAN, K. F. A influência de aspectos produtivos e da legislação ambiental na transformação da paisagem: o caso da microbacia do Rio Sete, São Bonifácio/SC. Geografia, Londrina, UEL, 17(1): 5-24, 2008.

BLEY JÚNIOR, C.; BASTOS, E. F. de; SIMONI, F.; BRUN, M. R.; LOCH, C. Código Florestal Brasileiro: considerações sobre o artigo segundo e dezesseis. Anais do Congresso Brasileiro de Cadastro Técnico Multifinalitário. Florianópolis: COBRAC, 2004. Disponível em www.geodesia.ufsc.br/geodesiaonline/arquivo/cobrac_2004/204.pdf. Acessado em 02/02/2007.

BRASIL. Lei Federal no 4.771/1965. Institui o Código Florestal Brasileiro. Brasília, 15 de setembro de 1965. Disponível em: www.planalto.gov.br. Acessado em 12/02/2007.

. Lei Federal no 6.938/1981. Institui a Política Nacional do Meio Ambiente. Brasília, 31 de agosto de 1981. Disponível em: www.planalto.gov.br/ccivil_03/Leis/L6938.htm. Acessado 12/02/2007. 
. Medida Provisória no 2.166/2001. Altera e complementa o Código Florestal Brasileiro. Brasília, 24 de agosto de 2001. Disponível em: www.planalto.gov.br/ccivil_03/MPV/2166-67.htm. Acessado em $13 / 02 / 2007$.

. Lei Federal no 11.428/2006. Lei da Mata Atlântica. Brasília, 22 de dezembro de 2006. Disponível em: www.planalto.gov.br/CCIVIL/_Ato2004-2006/2006/Lei/L11428.htm. Acessado em 13/02/2007.

Lei Federal $n^{\circ}$ 11.284/2006. Gestão de Florestas Públicas. Brasília, 02 de março de 2006. Disponível em: www.planalto.gov.br/CCIVIL/_Ato2004-2006/2006/Lei/L11284.htm. Acessado em 25/02/2007.

Resolução no 04/1994. Estágios sucessionais da Mata Atlântica. Brasília, 04 de maio de 1994. Disponível em: www.mma.gov.br/port/conama/res/res94/res0494.html. Acessado em 02/02/2007.

Resolução no 237/1997. Licenciamento ambiental. Brasília, 19 de dezembro de 1997. Disponível em www.mma.gov.br/port/conama/res/res97/res23797.html. Acessado em 02/02/2007.

Resolução $n^{\circ}$ 261/1999. Dispõe sobre os estágios sucessionais de vegetação de restinga para o Estado de Santa Catarina. Brasília, 30 de junho de 1999. Disponível em www.mma.gov.br/port/conama/ res/res99/res26199.html. Acessado em 02/02/2007.

Resolução no 303/2002. Dispõe sobre as Áreas de Preservação Permanente. Brasília, 20 de março de 2002. Disponível em www.mma.gov.br/port/conama/res/res02/res30302.html. Acessado em 02/02/2007.

Resolução $n^{\circ}$ 369/2006. Regulamenta a intervenção ou supressão de vegetação em Áreas de Preservação Permanente. Brasília, 28 de março de 2006. Disponível em www.mma.gov.br. Acessado em $02 / 02 / 2007$

BRASILEIRO BORGES, R. C. A proteção do meio ambiente frente ao direito de propriedade: a função ambiental da propriedade rural. Dissertação de Mestrado, UFSC, Programa de Pós-Graduação em Direito, Florianópolis, 1999.

COSTA, T. C. e C. da; SOUZA, M. G de; BRITES, R. S. Delimitação e caracterização de Áreas de Preservação Permanente por meio de um sistema de informações geográficas (SIG). Anais do VIII Simpósio Brasileiro de Sensoriamento Remoto, 1996, p. 121-127.

EPAGRI - Empresa de Pesquisa Agropecuária e Extensão Rural de Santa Catarina S.A. As experiências inovadoras do Grupo do Pasto na Microbacia do Rio do Poncho - São Bonifácio - SC. EPAGRI/Unidade de Planejamento Regional $\mathrm{n}^{\circ} 7$ - Proposta de Projeto de Pesquisa Participativa, 2005.

FATMA - Fundação do Meio Ambiente do Estado de Santa Catarina. Portaria no 018, de 2008. Regulamenta o cômputo da Área de Preservação Permanente no cálculo da área destinada a Reserva Legal. Disponível em: www.fatma.gov.sc.br. Acessado em 02/02/2007.

FEARNSIDE, P. M. Código Florestal Brasileiro: o perigo de abrir brechas. Ciência Hoje, São Paulo, 28 (163): 62-63, 2000.

HARTMAN, A. Ações judiciais paradigmáticas na Mata Atlântica. Proteção Judicial da Mata Atlântica em Santa Catarina. In: LIMA, A. (org.). Aspectos jurídicos de proteção da Mata Atlântica. Documentos ISA 7. ISA, São Paulo: 2001, p. 61-64.

IBGE - Instituto Brasileiro de Geografia e Estatística. Sinopse preliminar do Censo Demográfico de 2000. Disponível em www.ibge.gov.br. Acessado em 20/12/2006.

INSTITUTO CEPA - Instituto de Planejamento e Economia Agrícola de Santa Catarina. Síntese anual da agricultura de Santa Catarina 2000-2001. Instituto CEPA/Secretaria do Estado do Desenvolvimento Rural e da Agricultura, Florianópolis, 2001. 
Avaliação do valor bruto da produção agropecuária nas microrregiões geográficas de Santa Catarina 2000-2001. Instituto CEPA/Secretaria do Estado do Desenvolvimento Rural e da Agricultura, Florianópolis, 2002.

. Levantamento agropecuário de Santa Catarina 2002-2003. Instituto CEPA/Secretaria do Estado do Desenvolvimento Rural e da Agricultura, Florianópolis, 2005.

. Síntese anual da agricultura de Santa Catarina 2005-2006. Instituto CEPA/Secretaria do Estado do Desenvolvimento Rural e da Agricultura, Florianópolis, 2006.

JURAS, I. da A. G. M.; ARAÚJO, S. M. V. G. de. Projeto de Lei de conversão à MP 1956, que altera o Código Florestal. Brasília: Câmara dos Deputados, 2000.

KLEIN, R. M. Fitogeografia do estado de Santa Catarina. In: REITZ, R. (org.). Flora Ilustrada de Santa Catarina. Herbário Barbosa Rodrigues, Itajaí, 1978, p.1-24.

MACHADO, P. A. L. Direito ambiental e proteção das florestas. In: LEITE, J. R. M. (org.). Inovações em direito ambiental. Florianópolis, Fundação José Arthur Boiteux, 2000. p. 41-60.

MITTERMEIER, R. A.; FONSECA, G. A. B.; RYLANDS, A. B.; BRANDON, K. A brief history of biodiversity conservation in Brazil. Conservation Biology, 19(3): 601-607, 2005.

NEUMANN, P. S.; LOCH, C. Legislação ambiental, desenvolvimento rural e práticas agrícolas. Ciência Rural, Santa Maria, 32(2): 243-249, 2002.

RIBEIRO, C. A. A. S.; SOARES, V. P.; OLIVEIRA, S. M. A.; GLERIANI, J. M. O desafio da delimitação de Áreas de Preservação Permanente. Sociedade de Investigações Florestais, Viçosa, 29(2), 203-212, 2005.

SALLES, E. F. As percepções dos agricultores em relação às adversidades ambientais: o caso da sub-bacia do Rio Braço do Norte-SC. Dissertação de Mestrado, UFSC, Programa de Pós-Graduação em Agroecossistemas, Florianópolis, 2001.

SANTA CATARINA. Lei no 14.675/2009. Institui o Código Estadual do Meio Ambiente e estabelece outras providências. Florianópolis, 13 de abril de 2009. Disponível em: http://www.sc.gov.br. Acessado em 28/08/2009.

SCHADEN, F. Notas sobre a localidade de São Bonifácio, Santa Catarina. Anais do IX Congresso Brasileiro de Geografia, 1940, p. 7-40.

SUPREMO TRIBUNAL FEDERAL. ADI/4252 - Ação Direta de Inconstitucionalidade. Disponível em: http://www.stf.jus.br. Acessado em 28/08/2009.

TRENTINI, E. C. Agricultura "criminosa": atividades agrícolas avaliadas à luz do Código Florestal de 1965. Dissertação de Mestrado, UFSC, Programa de Pós-Graduação em Agroecossistemas, Florianópolis, 2004.

URBAN, T. Saudade do Matão: relembrando a história da conservação da natureza no Brasil. Curitiba: Editora da UFPR, 1998. 
FLORESTA, Curitiba, PR, v. 40, n. 2, p. 295-310, abr./jun. 2010 Alarcon, G. G.; Beltrame, A. da V.; Karam, K. F. 